\title{
Game techniques in developmental teaching the native language
}

\author{
Tamara Egorovna Andreeva*, Antonina Afanasyevna Vinokurova, Sargylana Danilovna \\ Vinokurova, Nadezhda Prokopyevna Nikolaeva, and Kirill Namsaraevich Struchkov \\ Institute for Humanities Research and Problems of Indigenous Peoples of the North, Siberian Branch \\ of the Russian Academy of Sciences, Department of Northern Philology, Yakutsk, Russia
}

\begin{abstract}
The purpose of this article is to show the possibility of in-depth teaching of the native language in an educational institution, the formation of communicative competence in children, the core of which is in communication skills; introducing students to a new social experience by playing various roles in the Evenk language in educational and game situations through didactic materials, including gaming techniques based on the Evenk language materials. Research hypothesis: gaming techniques in the classroom will form ideas about the native language as a means of knowing one's culture, promote in-depth teaching of the native language, stimulate the development of productive communication skills, gaining experience; motivate to learn the native language; purposefully listen to the teacher (classmates) when solving a cognitive task; help to obtain communicative results (communication skills by types of speech activity, conducting dialogues and monologues, etc.). The material was various scientific research on pedagogy, the experience of teachers of native languages applied in practice. The expected results of mastering the course "Native language (on the materials of the Evenk language") will form communicative, linguistic, socio-cultural, educational and cognitive competencies. In the learning process, didactic and creative games, visual aids, dramatization of fairy tales, etc. will be used. Didactic games, if used appropriately and included in the educational process competently, can become an effective means of enhancing the activities of students in the lessons of their native language (on the example of the Evenk language); help to create a language environment while working with senior participants, thus contributing to the development of the native speech of students, as they become active participants themselves. Games can be viewed as a means of developmental teaching, as a means of realizing entertaining learning, acquiring specific practical skills in children, as well as instilling in children a love of knowledge in general, as well as the native language and culture of the people.
\end{abstract}

Keywords: endangered languages, theory of education, theory of teaching, patterns of assimilation of knowledge, abilities and skills,

*Corresponding author: taan2001@mail.ru 
formation of beliefs, linguistic environment, native language, traditional culture

\section{Introduction}

The period from 2022 to 2032 was announced the International Decade of Indigenous Languages, this will draw attention to the problem of the extinction of indigenous languages and the need to preserve and popularize them at the national and international levels.

According to the UNESCO classification, the native languages of the peoples of the North of the Republic of Sakha (Yakutia) are endangered judging by the number of speakers [1].

Table 1. Language proficiency, $\%$.

\begin{tabular}{|l|c|c|c|}
\hline \multicolumn{1}{|c|}{ Nationality } & Native language & Russian language & Yakut language \\
\hline Evenki & 5.7 & $91.0 \%$ & $81.0 \%$ \\
\hline Evens & $22.3 \%$ & $91.4 \%$ & $76.8 \%$ \\
\hline Dolgans & $5.0 \%$ & $86.2 \%$ & $93.4 \%$ \\
\hline Yukaghirs & $22.6 \%$ & $97.0 \%$ & $49.6 \%$ \\
\hline Chukchi & $40.5 \%$ & $100 \%$ & $10.3 \%$ \\
\hline
\end{tabular}

Calculations are based on the results of the All-Russian Census of the Territorial Body of the Federal State Statistics Service for the Republic of Sakha (Yakutia).

As one can see, a negative linguistic situation has developed among the Northern peoples. In modern conditions, only the older generation speaks their native language, young people and children of the Northern peoples of the Republic of Sakha (Yakutia) speak only Russian and Yakut languages, they do not know their native language.

Linguistic education at the school of the 21 st century intends to realize the potential of the native language (based on the Evenk language materials) as a means of communication, understanding the surrounding world, self-development of a student as a person with his/her own interests-these are the tasks that the school sets in the humanities education sector for the national groups.

The Soviet system of upbringing children of the indigenous peoples of the North, their education in boarding schools led to disruption of the continuity of generations, separation of children from the traditional occupations of their parents, from the language and culture of their native people. Therefore, qualitatively new approaches to the implementation of the national language policy in the country are required, and the system of upbringing and teaching children of the Northern peoples must be updated [2].

In modern society, a lot of attention is paid to the search for new forms, methods and techniques of teaching. The modern school needs such teaching methods that could not only provide high-quality training, but also open up the personality of a person, creative potential of an individual.

The purpose of this article is to show the possibility of in-depth teaching of the native language (on the materials of the Evenk language) with the help of gaming techniques in the formation of communicative competence in children.

Research hypothesis: gaming techniques in the classroom will contribute to in-depth teaching of the native language, act as a link between academic subjects to build a holistic 
picture of the process being studied, stimulate the development of productive communication skills and gaining experience.

In modern society, much attention is paid to the search for new forms, methods and techniques of teaching the native language. Unfortunately, the gaming method in teaching is used very rarely, although the communicative method implies numerous options for gaming teaching methods. They foster a positive emotional attitude of students, increase their motivation.

\section{Results}

Didactic games, if used appropriately and included in the educational process competently, can become an effective means of enhancing the cognitive activity of students in their native language lessons (on the example of the Evenk language); achieve personal, metadisciplinary, communicative results.

\section{Discussion}

The concept of "gaming pedagogical technologies" includes an extensive group of methods and techniques for organizing the pedagogical process in the form of various pedagogical games $[3,4]$.

Froebel was one of the first to classify a game as an educational phenomenon. His game theory was the foundation of his pedagogical theory [5].

Groos was the first to attempt a systematic study of the game at the end of the 19th century. Objectively, a game is an elementary school, which gives a child the opportunity to learn about traditions of behavior of the people around. The development of the gaming method played a special role in the modern formation of game teaching, which was mainly based on the use of business games, which served as the basis for the development of a large group of teaching methods called active learning methods. In theory, their use has been demonstrated in a number of concepts, primarily in the theory of active learning [6].

Elkonin believed that "a game is social in nature, instantly saturated and projected in the reflection of the adult world". Russian psychologists and educators understood the development process as the assimilation of universal human experience and universal values [7].

Thus, a game is an innovation that helps a child believe or not believe everything that happens in the plot of the game. In many games, the "reality function" is present either in the form of narrative conditions, or in the form of anchor objects, or in the game intrigue itself [8-11].

A game is a means of a child's search for himself/herself among peers, in society as a whole, in the humankind, in the universe, access to social experience, culture of the past, present and future, and repetition of understandable social practice. This is a unique phenomenon of world human culture, its source and climax. In no kind of activity, a person shows such forgetfulness, revealing their psychological and physiological capabilities, as in a game. A game is a regulator of all situations in a child's life. A game is a school in which the child learns and studies at the same time [12].

In the 1970s, developmental games occupy an important place among modern educational and psychological learning technologies. Today, in Russia, the USA and other developed countries, there is no educational institution that does not use business games or game teaching methods. 
Pedagogical theory which emerged in the Soviet education system, intensified the use of games in the teaching process of preschool institutions, but in practice it did not bring games to schoolchildren, adolescents and young people.

In 2009, the All-Russian Association for Games (RAGE) was founded. Its main goal was development of education based on gaming technologies. Introduction of gaming technologies into the educational process is the requirement of the Federal State Educational Standard [13]. The standard considers a game as a means that can transform the educational sector into a technological space. This issue is most thoroughly presented in the work by Selevko. The researcher sees that gaming technologies are characterized by a specially defined goal that corresponds to the learning outcome, and in gaming technologies it is "a type of activity in situations aimed at reconfiguring and assimilating social experience in which self-management of behavior develops and improves". The importance of the role and place of gaming technologies in the educational process largely depends on how the teacher understands their functions. Summarizing the previous experience, Selevko singled out the entertaining, communicative, therapeutic, diagnostic, correcting, socializing, interethnic communication [14].

The value of a game is determined by the effectiveness in solving a particular problem in relation to each student. The effectiveness of games depends on their systematic use, the purposefulness of the games program in combination with ordinary didactic exercises. Games can be divided into five main groups: board games, didactic games, mobile, business games, intellectual games. Let us consider some examples of board, didactic and intellectual games.

\subsection{Board games [15]}

Turerve tavkallu [Make up the words] You need to make a word from scattered letter cards.

For example, cards with letters are scattered (Fig. 1):
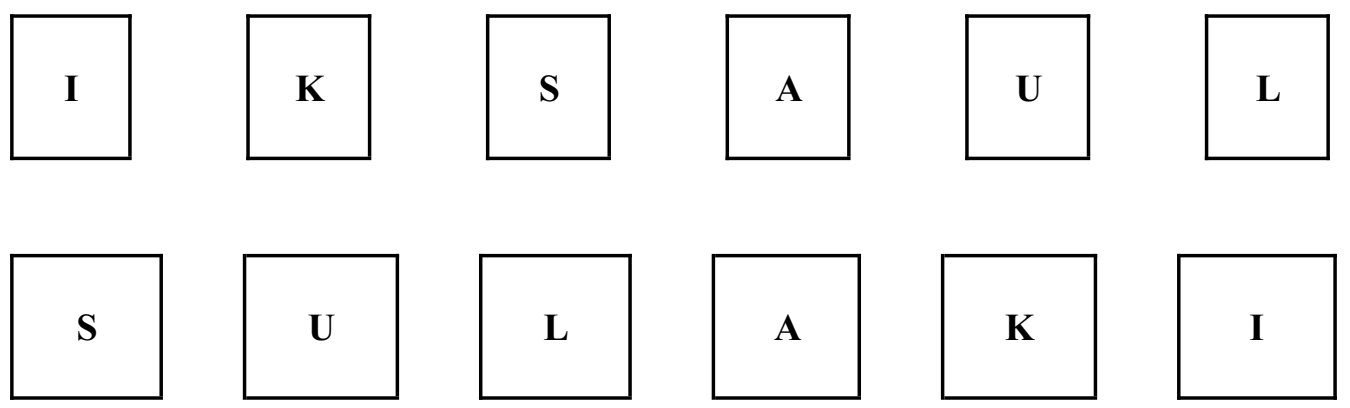

Fig. 1. Card's example.

They have to make up the word sulaki [fox] in picture puzzles (Table 2).

Table 2. Picture example.

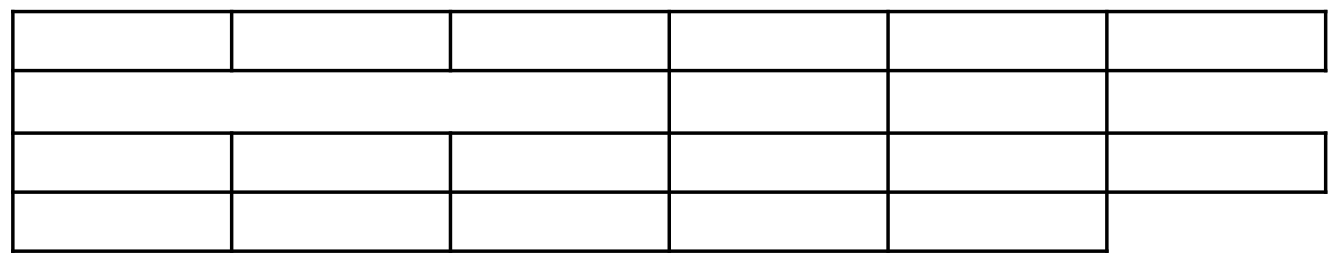




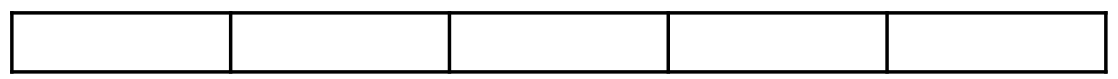

Write the names of the trees horizontally:

chalban [birch]

mo [tree]

irekte [larch]

secan [purple willow]

Children's games educate, develop in the child all the wealth of the human personality. A child should play in childhood the same way an adult should work. After all, a game is children's creativity. And the teacher skillfully uses this creative ability for educational purposes. This way, the constant interest of children in the educational process is maintained, words are easily learned in the game, skills are created in the use of words in colloquial speech.

Crosswords and pictorial puzzles, as a kind of board games, can be performed on a school board, a piece of Whatman paper, or on separate cards that serve as handouts. They can be used in integrated or roundup lessons, and for testing knowledge. They represent one of the stages of the lesson. A pictorial puzzle is a game in which words, a phrase or whole statements are encrypted. To compose and read a pictorial puzzle, you need to know certain rules, go from simple to complex, explaining the clues to solve it. Children are very fond of puzzles and crosswords.

\subsection{Didactic games of natural history [16]}

Example 1. Eviget! [Let's play!] Find the names of the months in table 3.

Table 3. Letters to find words.

\begin{tabular}{|l|l|l|l|l|l|l|l|l|l|}
\hline E & s & m & u & c & u & n & g & h & n \\
\hline K & h & E & L & O & G & A & I & S & T \\
\hline T & U & P & A & R & U & G & R & A & S \\
\hline E & G & I & S & O & N & K & A & N & I \\
\hline N & D & A & A & L & Y & P & V & E & R \\
\hline K & A & L & M & I & P & E & U & G & U \\
\hline I & R & K & I & N & T & I & N & I & D \\
\hline R & P & O & R & T & U & R & A & N & Y \\
\hline E & I & h & E & G & D & I & G & U & N \\
\hline s & i & e & K & T & I & G & E & h & E \\
\hline Clue: & \multicolumn{1}{|l|l|l|l|l|l|l|l|l|l|l|}{} \\
\hline E & S & m & u & c & u & n & g & & \\
\hline K & h & \multicolumn{1}{|l|l|l|l|l|l|l|l|l|l|l|}{} \\
\hline T & U & & R & U & & I & & \\
\hline E & G & & S & O & N & K & A & N & I \\
\hline N & D & & L & & & V & & R \\
\hline K & A & & M & I & & & U & & U \\
\hline I & R & K & I & N & & & N & & D \\
\hline R & P & & R & T & U & R & A & N & Y \\
\hline E & I & h & E & G & D & I & G & & N \\
\hline
\end{tabular}

These games can be carried out during walks, excursions and in the classroom, to generalize knowledge about specific concepts of nature in the native language. 
Example 2. Verbal didactic game "An absent-minded man": he cannot remember relatives and keeps asking: Er nini? [Whose is this?] How to answer this question in your native language?

minni eniv [my mother]

sinni enis [your mother]

\subsection{Intellectual games}

Guessing riddles can be viewed as a creative process, and the riddle itself as a creative task. Purposeful development of intellectual abilities assumes the teacher's knowledge of the mechanisms for constructing riddles, since the nature of the mental operations to be performed by the guessing person is determined by the type of construction of a logical task, the method of encrypting the object or phenomenon in the riddle. Examples:

1) Riddles in which a description of an object or phenomenon is given by listing signs:

Minemi, minemi - sekseeachin, nenemi, nenemi - udyalachin. (Onkocho)

[It cuts and cuts - there is no blood, it goes and goes - there are no traces. (Boat)]

Riddles where the description offers a brief characteristic of an object or phenomenon:

Agidu vek deromidyavki. (Dyantaki)

[It constantly steals things in the taiga. (Wolverine)]

The value of these games lies in their cognitive potential: with their help, one can correct and develop personal qualities in children.

\section{Conclusion}

Thus, games can be viewed as a means of developmental teaching, as a means of realizing entertaining learning, acquiring specific practical skills in children, as well as instilling in children a love of knowledge in general, the native language and culture of the people.

\section{References}

1. Nematerialnoe nasledie [Intangible heritage]. Bulletin, (2006). Accessed on: October 8, 2021. [Online]. Available: https://ich.unesco.org/doc/src/00843-RU.pdf

2. J.A. Comenius, Izbrannye pedagogicheskie raboty [Selected pedagogical works]. (Moscow, 1939)

3. V. Gabdulchakov, Procedia - Soc Behav Sci, 233, 170-174 (2016). https://doi.org/10.1016/j.sbspro.2016.10.187

4. R. Nagovitsyn, Rev Roman Educ Multidim, 12(4), 156-171 (2020). https://doi.org/10.18662/rrem/12.4/339

5. F.W.A. Froebel, Let us live for our children: Art., advice and recommendations. (Karapuz, Moscow, 2001)

6. K. Groos, Des Seelenleben des Kindes [Of the child's soul life]. (Kiev, 1916)

7. D. Elkonin, Psihologyaigri. (Vlados, Moscow, 1999)

8. U. Tolipov, F. Tolipova, Adv Sci J, 3, 29-31 (2015).

https://doi.org/10.15550/ASJ.2015.03.029 
9. M. Stakhiv, O. Kovalska, H. Marko, Young Sci, 9(73), 99-103 (2019). https://doi.org/10.32839/2304-5809/2019-9-73-22171

10. M. Leshchenko, L. Khimchuk, Aesth Ethics Pedag Act, 21 (2020). https://doi.org/10.33989/2226-40512020.21.218093

11. E.N. Vaseva, D.M. Kuznetsova, N.A. Rzhanova, Bul Shadrinsky State Pedag Univ, 1(49), 25-29. https://doi.org/10.52772/25420291.2021.125

12. J. Rugelj, The pedagogical challenges in theory and practice, in Didactic games in education, 355-370. (University of Ljubljana, 2014)

13. Federalnyi gosudarstvennyi obrazovatelnyi standart [federal state educational standard]. Accessed on: October 8, 2021. [Online]. Available: https://fgos.ru/

14. G.K. Selevko, Pedagogicheskie tekhnologii, osnovannye na effektivnosti upravleniya i organizatsii obrazovatelnogo protsessa [Pedagogical technologies based on the effectiveness of management and organization of the educational process]. (Vintazh, Moscow, 2011)

15. N.E. Zakharova, K.N. Struchkov, Evedisakellu. Znat evenkiiskii yazyk (uchebnoe posobie dlya 5-9 klassov) [Evedisakellu. Know the Evenk language (teaching aid for grades 5-9)]. (Yakutsk, 2006)

16. Itogi VPN-2010. (2010). Accessed on: November 9, 2021. [Online]. Available: http://gks.ru/free_doc/new_site/perepis2010/croc/perepis_itogil612.htm 